\title{
Experimental Study of Fracture Characterizations of Rocks under Dynamic Tension Test with Image Processing
}

\author{
Dihao Ai $(\mathbb{D}$, Yuechao Zhao $(\mathbb{D}$, Beijing Xie $(\mathbb{D}$, and Chengwu Li $(\mathbb{D}$ \\ College of Resources and Safety Engineering, China University of Mining and Technology, Beijing 100083, China \\ Correspondence should be addressed to Chengwu Li; lcw@cumtb.edu.cn
}

Received 28 April 2019; Accepted 17 June 2019; Published 1 July 2019

Academic Editor: Stefano Manzoni

Copyright (c) 2019 Dihao Ai et al. This is an open access article distributed under the Creative Commons Attribution License, which permits unrestricted use, distribution, and reproduction in any medium, provided the original work is properly cited.

\begin{abstract}
To investigate the fracture characterizations of rocks under high strain rate tensile failure, a series of dynamic Brazilian tests was conducted using Split Hopkinson pressure bar (SHPB), and a high-speed digital camera at a frame rate of 50,000 frames per second (FPS) with a resolution of $272 \times 512$ pixels was adopted to capture the real-time images and visualize the failure processes. Using the extracted cracks and image processing technique, the relationship between loading condition (impact velocity), crack propagation process (crack velocity, crack fractal characteristic, and crack morphological features), and dynamic mechanical properties (absorbed energy and strain-stress parameters) was explored and analyzed. The experimental results indicate that (1) impact velocity plays a critical role in both crack propagation process and dynamic mechanical properties, $(2)$ the crack fractal dimension is positively correlated with crack propagation velocity and has a linear relationship with the proposed morphological feature of crack, (3) mean strain rate and max strain of rocks under SHPB loading both decrease with the increase of crack propagation velocity, and (4) the energy absorbed by the rocks increases with increasing impact velocity and has a strong negative correlation with a proposed novel crack descriptor. Experimental studies pertaining to the measurement of crack propagation path and velocity, in particular, some crack feature extraction approaches, present a promising way to reveal the fracture process and failure mechanisms of rock-like materials.
\end{abstract}

\section{Introduction}

Fully understanding the dynamic rock mechanics is of great importance in dealing with a wide range of civil engineering applications, e.g., earthquakes, mining, subway tunnel excavation, blasting events, and protective construction project $[1,2]$. The properties of rocks under dynamic loading tests always are very different from those of static tests due to the transient nature of high strain rate loading; therefore, several testing methods for determining the dynamic properties and fracture behavior of rocks have been conducted over the past few decades, e.g., Brazilian disc (BD) [3, 4], semicircular bending (SCB) [5, 6], notched semicircular bending (NSCB) [7-9], cracked chevron notched BD (CCNBD) [10], cracked chevron NSCB (CCNSCB) [11], flattened BD (FBD) [12], and holed cracked FBD (HCFBD) [13]. Additionally, the dynamic mechanical behavior of rock materials under different test conditions has been extensively studied, e.g., dynamic uniaxial compressive test, dynamic triaxial compressive test, dynamic tensile test, and dynamic shear test. For example, Lundberg [14] performed some compression tests on rock-like materials using the SHPB technique. Isheyskiy and Marinin [15] investigated the strength of blasted rocks accounting for fracture zones and explored the relationship between uniaxial compressive strength of average rock and energy consumption. Gary and Bailly [16] applied some improved loading technique to determine the triaxial compressive strength of rock-like materials. Zhao et al. [17] investigated the dynamic shear strengths of rock-like materials using a pneumatichydraulic machine.

Moreover, it has been generally recognized that rock and rock-like materials are much weaker in tension than compression. Therefore, accurate determination of dynamic response and fracture properties of rocks under high strain rate tensile failure is important. In general, dynamic tension testing methods are being continuously improved from the 
original quasistatic ones to precisely determine the dynamic tensile strength which can be approximately classified into two categories: direct tensile and indirect tensile testing methods [1]. Compared with the direct testing method to measure the tensile strength of rock material, an indirect testing method provides a more convenient and accurate alternative not only for the specimen preparation but also for the experimental design [18].

More specifically, the primary testing methods to determine the dynamic tensile strength of rock are basically extended from corresponding quasistatic ones and mainly include BD or FBD method, bending [19] or SCB method [5], spalling method [20-22], etc. Specifically, Zhou et al. [3] and Zhao et al. [4] conducted several tests on rock specimens with BD configuration using a SHPB and investigated the dynamic indirect tensile strength of rocks under different loading conditions. Dai et al. [5, 6] explored the rate dependence of tensile strength of rocks under SHPB impact loading using SCB. Biolzi and Labuz [23] investigated the deformation of a rock specimen in the classical four-point bend (FPB) fracture tests. Wang et al. [24] also assessed the FPB method for testing the tensile strength and fracture toughness of rocks by using the SHPB apparatus. Klepaczko and Brara [20] performed a dynamic tensile test for concreate using spalling method. In addition to the above indirect tension test, Asprone et al. [25] investigated the dynamic behavior of rock-like materials using the dynamic DT (Direct tension) method. Among these, the BD test is widely used for measuring the static and dynamic fracture toughness of rock and rock-like materials under the Split Hopkinson pressure bar (SHPB) loading. SHPB is a highly reliable apparatus and widely utilized to quantify the dynamic properties of rocks under high strain rates since it was invented by Kolsky in 1949 [26], and many efforts have been made to improve the measurement results [27, 28]. Moreover, these experiments always are conducted to explore the dynamic mechanical properties of rocks as well as crack initiation, propagation, and coalescence under different SHPB loading rates [11, 29-31]. For example, Zhang and Zhao [32] performed an experimental investigation about quasistatic and dynamic fracture behavior of rock materials by a servohydraulic and SHPB loading system. Bertram and Kalthoff [33] investigated the Mode-I propagation processes for limestone material under different crack speeds and explained the characteristics of the crack propagation path of brittle materials based on the experimental results. Also in Mode-I rock fracture process, Dai et al. [11] and Chen et al. [34] employed SHPB and laser gap gauge to study the dynamic fracture properties of rock-like materials with CCNSCB and SCB configuration, respectively. Forquin [35] proposed a crack velocity measurement method using optical correlation technique for concrete and rock-like materials under dynamic tensile loading test. Zhao et al. [36] also adopted a high-speed digital camera to record the crack propagation process of coal materials under SHPB impact loading and explored its fractal characteristics. Gomez et al. [37] performed a photoelastic dynamic splitting experiment and studied the dynamic behavior of concrete and granite with tensile damage.

Since dynamic fracture of rock material is a very complex behavior, some traditional contact measurement approaches like resistance strain gauges cannot provide enough information to reveal the dynamic fracture process of rock. Therefore, many noncontact and optical measurement techniques have been adopted and developed as a promising way in the experiment to record the fracture process and further reveal the fracture process and failure mechanisms of rock materials [38]. These techniques can be approximately classified into following groups, i.e., CT (computed tomography) [39, 40], SEM (scanning electron microscope) $[41,42]$, X-ray phase contrast imaging (PCI) [43, 44], LGG (laser gap gauge) [34, 45], DIC (digital image correlation) [46-48], and DIT (dynamic infrared tomography) [49]. Among them, using the high-speed \& high-resolution camera is the most convenient way to capture the fracture process of rock material.

Nevertheless, with regard to the crack evolution characteristics and failure process, the investigation is more challenging than that of stress-strain on the rock specimen in SHPB experiments since there are no effective characteristic parameters that can quantitatively describe crack propagation. To the best of our knowledge, research studies into the relationship between crack propagation and mechanical properties are relatively few. Therefore, we proposed a data processing method based on Ratsnake graphic annotation software [50] and Halcon machine vision software [51] to extract crack propagation features which are further compared with the dynamic mechanical properties of rocks. The main aim of this study is to visualize the relationship between crack propagation process and mechanical properties of rock using extracted multicracks and then, to investigate and reveal the future fracture behavior of the rock materials.

\section{Experiment Procedures}

2.1. Experimental Design and Rock Specimens. The dynamic Brazilian tensile test is conducted using the SHPB system at China University of Mining and Technology Beijing (CUMTB), and the schematic and physical map of the experimental setup are shown in Figures 1 and 2, respectively.

The SHPB system mainly consists of power system, bars, strain wave collector, and high frame rate camera. In order to satisfy the one-dimensional stress wave propagation wave, the length of the bars should be 30 times of the bar diameter [3]. Therefore, the length and the diameter of the bars utilized in the experiment are $2000 \mathrm{~mm}$ and $50 \mathrm{~mm}$, and the length and diameter of the bullet are $400 \mathrm{~mm}$ and $50 \mathrm{~mm}$. In addition, all the bars used in the SHPB test are 35CrMn steel material with $7,800 \mathrm{~kg} / \mathrm{m}^{3}$ density, $206 \mathrm{GPa}$ Young's modulus, and 0.28 Poisson's ratio.

To visualize the fracture process and further reveal fracture mechanism, FASTCAM SA5 (16G) camera was employed to capture the fractured images of rock, which adopts the CMOS sensor with a $20 \mu \mathrm{m}$ pixel delivering an 


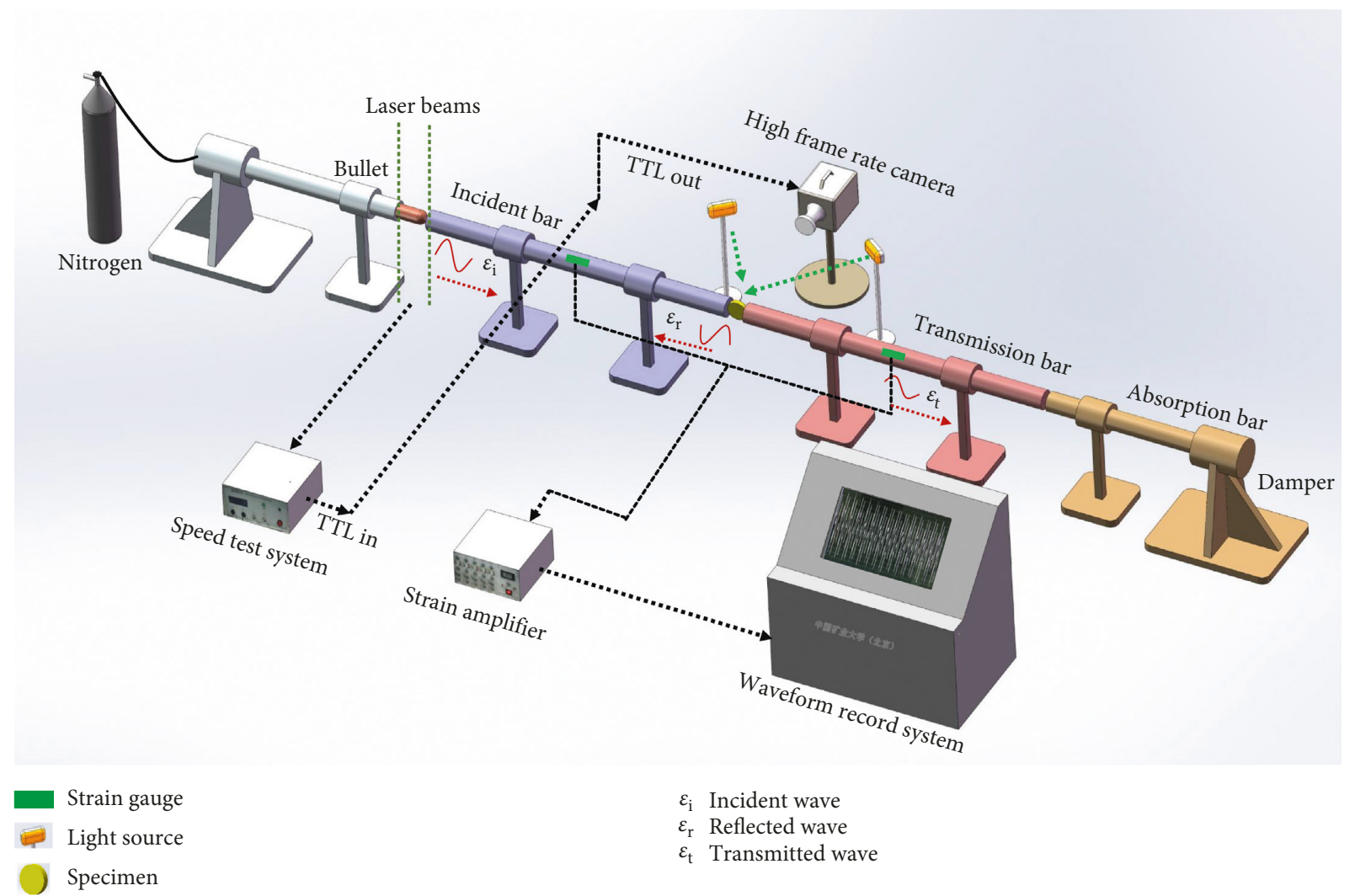

FIgURE 1: Schematic map of the SHPB experimental system.

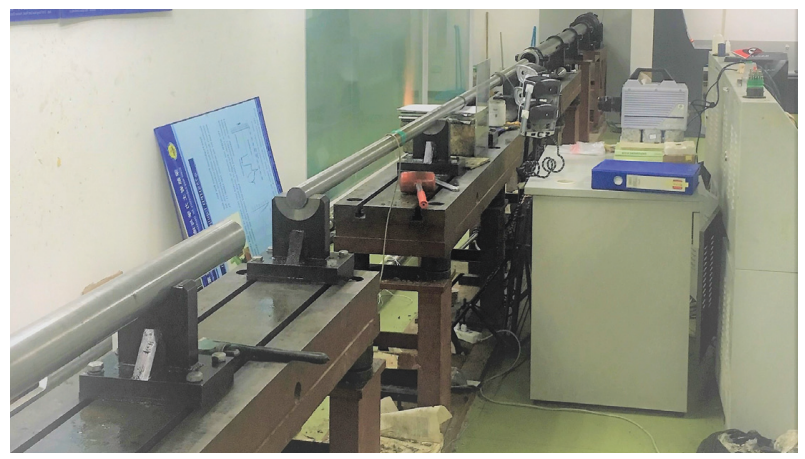

Figure 2: Physical map of the SHPB experimental system.

ISO light sensitivity of 10,000 monochrome and 4,000 colors. When the frame rate is set to $1,000,000 \mathrm{FPS}$, the resolution of the captured image is only $16 \times 64$ pixels; on the other hand, when the resolution is set to $1024 \times 1024$, the maximum frame rate is only 7000 FPS which cannot capture the fracture process of a rock specimen under SHPB impact loading. Therefore, the camera is set to $272 \times 512$ pixels resolution at a frame rate of 50,000 FPS in the experiment.

The rock samples utilized in the experiment are manufactured by sandstone selected from a quarry in the Fangshan area of Beijing, China. According to the ISRM suggestion for $\mathrm{BD}$ specimens preparation, the rock specimens were cut from the same rock block without obvious bedding and manufactured to a cylinder with a dimension of $50 \mathrm{~mm}$ in diameter and $25 \mathrm{~mm}$ in length. Moreover, two ends of the rock specimen were finely ground to be flat within an accuracy of $\pm 0.05 \mathrm{~mm}$ and perpendicular to the longitudinal axis no more than $\pm 0.25^{\circ}$. At last, the surface of the rock samples is smooth by Vaseline lubricant.

2.2. SHPB Test. SHPB is an ideal apparatus for testing the dynamic response of materials, and its principle is based on the one-dimensional (1D) stress wave propagation. To accurately calculate the dynamic properties of rock material under SHPB loading, the following three assumptions also require to be satisfied [1]: (1) propagation of elastic waves in the bars satisfied 1D stress wave theory which determined by the bar dimensions; (2) neglecting the friction and inertia effects on the rock specimen which can be fulfilled approximately with the suggested testing procedures; (3) specimen reaches stress equilibrium. For a classic SHPB test, when the bullet impacts the incident bar, a compressive pulse is generated and propagates towards the rock sample. With the above recorded incident $\varepsilon_{\mathrm{i}}(t)$, reflected $\varepsilon_{\mathrm{r}}(t)$, and transmitted $\varepsilon_{\mathrm{t}}(t)$ strain signals, the stress $\sigma(t)$, strain $\varepsilon(t)$, and strain rate $\dot{\varepsilon}(t)$ of rock material under different impact velocities can be expressed as 


$$
\begin{aligned}
& \sigma(t)=\frac{A E}{2 A_{\mathrm{S}}}\left[\varepsilon_{\mathrm{i}}(t)+\varepsilon_{\mathrm{r}}(t)+\varepsilon_{\mathrm{t}}(t)\right], \\
& \varepsilon(t)=\frac{C}{L_{\mathrm{S}}} \int_{0}^{t}\left[\varepsilon_{\mathrm{i}}(t)-\varepsilon_{\mathrm{r}}(t)-\varepsilon_{\mathrm{t}}(t)\right] d t, \\
& \dot{\varepsilon}(t)=\frac{C}{L_{\mathrm{S}}}\left[\varepsilon_{\mathrm{i}}(t)-\varepsilon_{\mathrm{r}}(t)-\varepsilon_{\mathrm{t}}(t)\right],
\end{aligned}
$$

where $A$ and $A_{\mathrm{S}}$ are the cross-sectional area of the bar and rock specimen, respectively. $E$ is Young's modulus of the bar, $C$ is the longitudinal stress wave speed of the bar, and $L_{\mathrm{S}}$ denotes the length of rock specimen.

Also, the dynamic forces on the incident and transmitted ends, $P_{1}$ and $P_{2}$, can be computed as

$$
\begin{aligned}
& P_{1}=A E\left(\varepsilon_{\mathrm{i}}+\varepsilon_{\mathrm{r}}\right), \\
& P_{2}=A E \varepsilon_{\mathrm{t}} .
\end{aligned}
$$

\section{Methodology}

Figure 3 shows the framework of our proposed method, which mainly consists of two parts, i.e., crack feature extraction and dynamic mechanical properties calculation. Firstly, the video of the fracture process of rock specimens is split into several images which will be postprocessed by the crack extraction module. To achieve the accurate extraction of cracks, a novel and efficient image annotation software tool, Ratsnake [50], is adopted to identify and extract cracks on rock surface accurately. According to the principles of connected domain approach used in semantic image segmentation application, images of extracted cracks of rock specimens under SHPB impact loading are obtained. Then by Halcon [51] machine vision software, a number of novel crack features have been proposed and calculated to describe the fracture process of rock under different loading rates. At the same time, dynamic mechanical properties also have been computed based on the above formulas. Finally, a correlation matrix was constructed based on Pearson's correlation coefficient.

As illustrated in Figure 4, the correlation matrix heatmap has been calculated based on the experimental data to visualize the relationship between loading condition, crack propagation process, and dynamic mechanical properties of rocks under different SHPB impact velocities.

Given paired data $\left\{\left(x_{1}, y_{1}\right), \ldots,\left(x_{n}, y_{n}\right)\right\}$ consisting of $n$ pairs, Pearson's correlation coefficient $r_{x y}$ is defined as

$$
r_{x y}=\frac{\sum_{i=1}^{n}\left(x_{i}-\bar{x}\right)\left(y_{i}-\bar{y}\right)}{\sqrt{\sum_{i=1}^{n}\left(x_{i}-\bar{x}\right)^{2}} \sqrt{\sum_{i=1}^{n}\left(y_{i}-\bar{y}\right)^{2}}},
$$

where $n$ is the sample size, $x_{i}, y_{i}$ are the individual points indexed with $i$, and $\bar{x}, \bar{y}$ are the sample mean values of $x$ and $y$ points.

In the correlation matrix heat-map, larger positive values were represented by dark red colors denoting a strong positive correlation between two variables while larger negative values were represented by dark blue colors which indicate a strong negative correlation between two variables.

\section{Results and Discussion}

\subsection{Crack Propagation Process}

4.1.1. Crack Propagation Velocity. Over the past few decades, there have been some investigations for crack propagation velocities of rock materials under dynamic loading which provide a promising way to explore the fracture mechanisms of rock materials [1, 18]. However, relatively few crack extraction approaches based on image processing have been conducted on rock specimens to describe the failure process and explore the fracture mechanism due to the technical difficulties associated with crack feature extraction and computation.

In this study, the crack propagation velocity $V$ and $V_{A_{\mathrm{p}}}$ were calculated according to the crack length and crack area (the number of crack pixels) [52], as shown in Figures 5 and 6.

To visualize the relationship between these two crack velocity variables, Figure 7 plots $V_{A_{\mathrm{p}}}$ as a function of $V$ as well as the fitting curve. It can be seen that $V_{A_{\mathrm{p}}}$ increases almost linearly with the increased of $V$ under SHPB loading.

4.1.2. Crack Fractal Characteristic. Since cracks on rock surface are an important index to measure the state of rock material and fractals exhibit the ability for measuring the complex topological pattern, many significant endeavors have been made to investigate the fractality of cracks to the mechanics of fracture $[53,54]$.

In mathematics, a fractal dimension is used to evaluate the fractal patterns by quantifying their complexity as a ratio of the change in detail to the change in scale [55]. Unlike topological dimensions, the fractal dimension can take noninteger values. Particularly, there are many formal mathematical definitions for fractal dimension, e.g., boxcounting dimension, information dimension, and correlation dimension. Among them, the box-counting dimension is calculated by counting how this number changes as it makes the grid finer by applying a box-counting algorithm. In more detail, by the box-counting dimension computation method, the fractal dimension of an object can be computed as [56]

$$
N=C \cdot S^{D}
$$

where $D$ is fractal dimension, $S$ the scale of the object (cracks), $N$ the number of boxes of scale $S$ required to cover the object (cracks), and $C$ a constant number. Taking the logarithm, it can be rewritten:

$$
\ln N=\ln C+D \cdot \ln S
$$

Therefore, the box-counting dimension $D$ can be defined as

$$
D=-\lim _{s \rightarrow 0} \frac{\ln N}{\ln S} .
$$




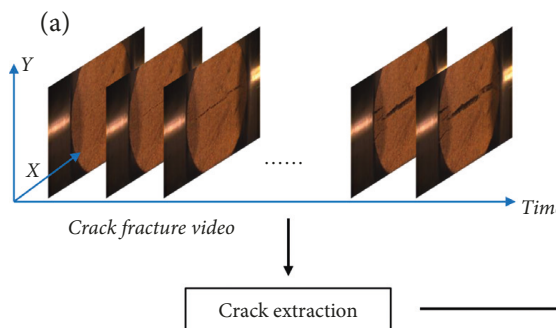

(b)
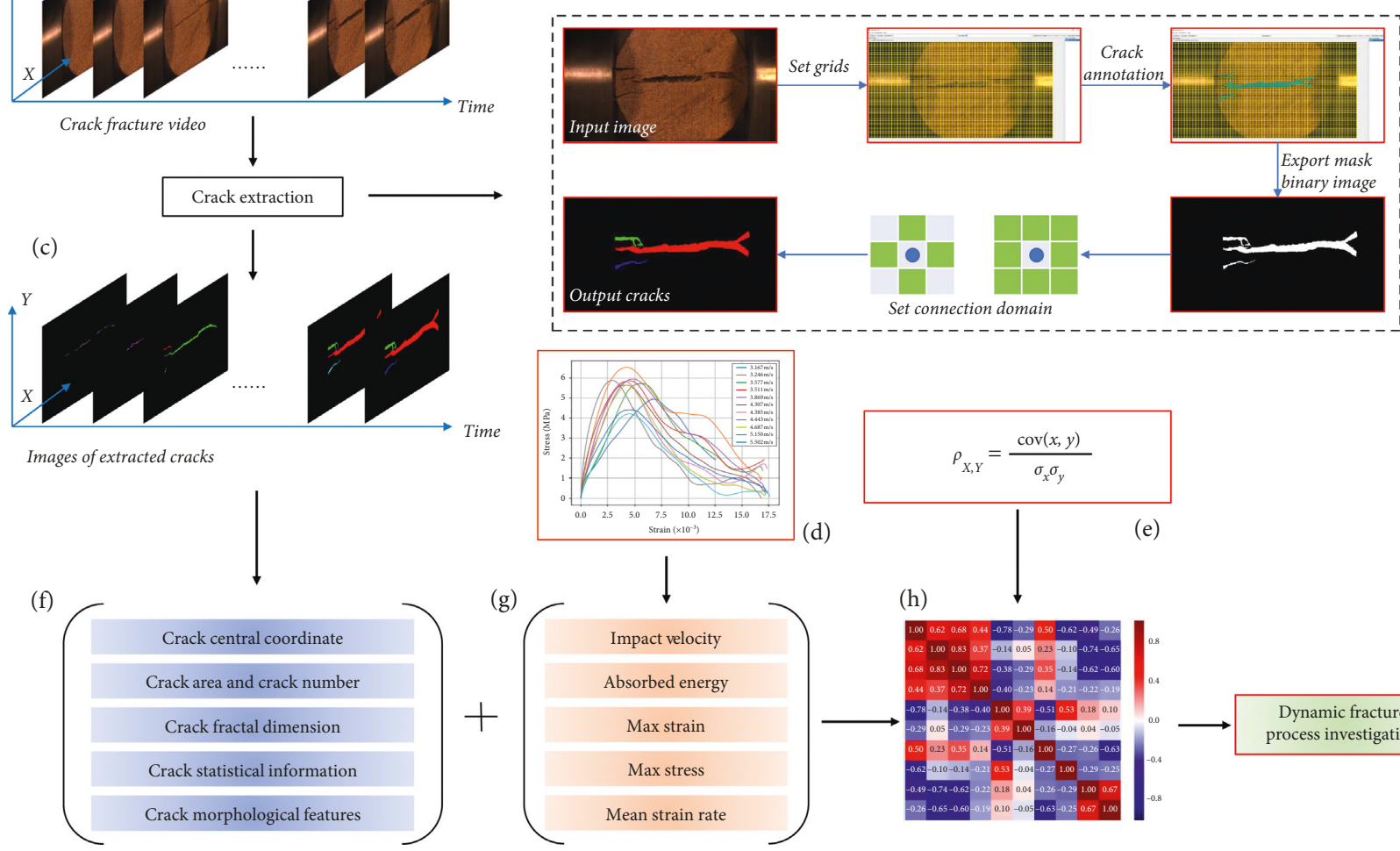

(h)

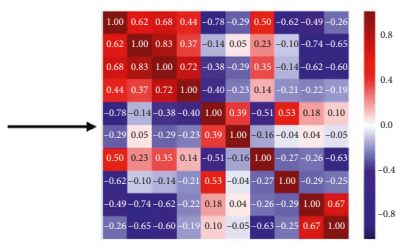

Dynamic fracture process investigation

FIGURE 3: An overview of the proposed approach for the investigation of dynamic fracture process of rock materials under SHPB impact loading. (a) an input video of rock fracture process; (b) an algorithm for multicracks extraction; (c) crack extraction results for a fracture process video; (d) dynamic strain-stress response of rock specimens; (e) the formula of Pearson's correlation coefficient; (f) matrix of crack evolution features; (g) matrix of dynamic mechanical properties; (h) a correlation matrix heat-map of relationship between crack evolution features and dynamic mechanical properties.

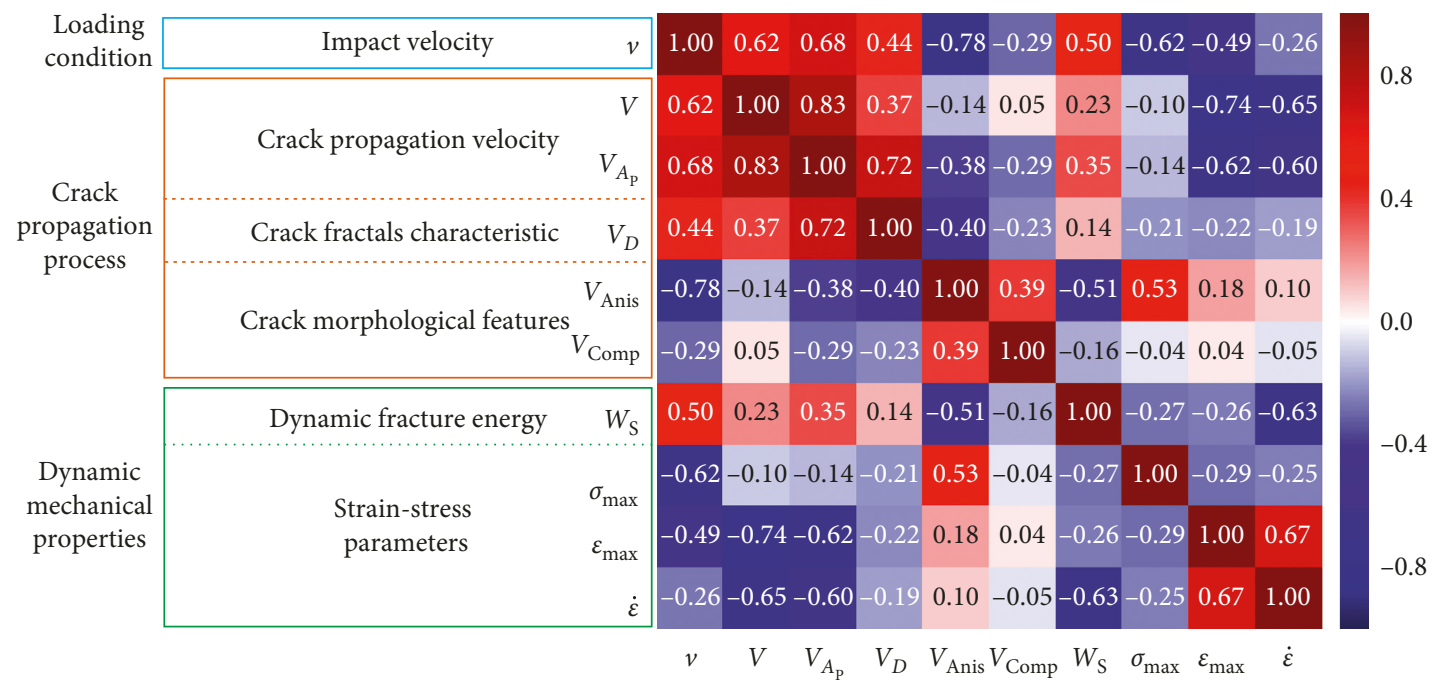

FIGURE 4: An illustration of the correlation matrix heat-map with loading condition, crack propagation process, and dynamic mechanical properties.

Figure 8 presents an illustration for crack coverage using different scale boxes $(S=8,16,32,64)$, while Figure 9(a) plots the linear fitting results of $\ln N$ and $\ln S$, which shows the fractal dimension is 1.14 for current cracks on rock surface. Based on the plots of $\ln N$ and $\ln S$, the fractal dimension of the crack can be accumulated by formula (8).

In general, the higher fractal dimension indicates a more curved and intricate crack propagation path. Therefore, according to the above method, the fractal dimension of 


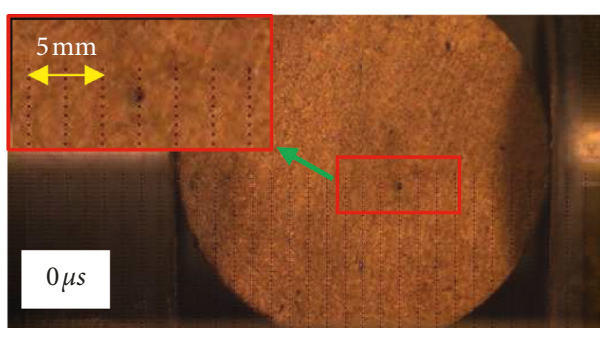

(a)

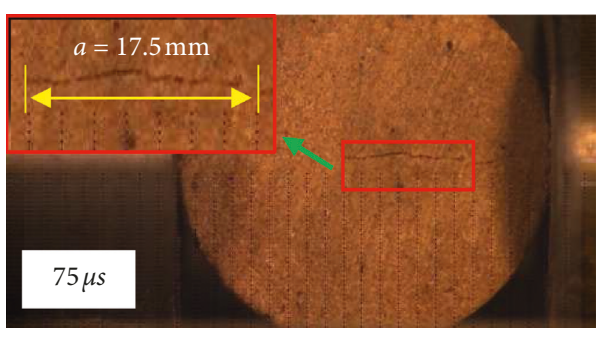

(b)

FIGURE 5: An illustration of crack propagation velocity computation using crack length.

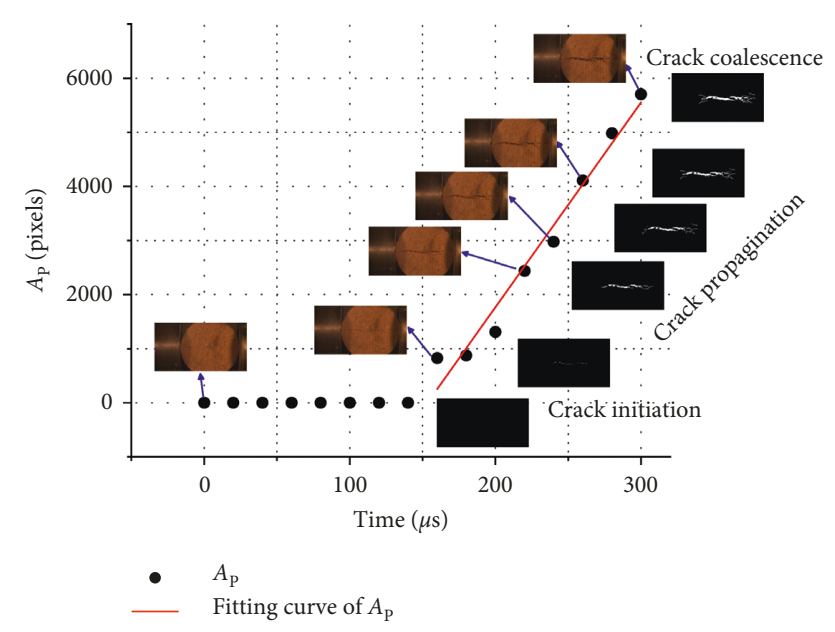

FIGURE 6: An illustration of crack propagation velocity computation using crack area.

cracks in each frame of the rock fracture process has been increasing. Figure 9(b) gives a quantitative description of the crack propagation process of rock specimens under different impact velocities. It can be observed from it that the fractal dimension of cracks increases gradually during the fracture process of rocks, and the value of the fractal dimension of cracks on rock surface ranges from 0.8 to 1.2 .

Figure 10 shows the relationship between crack propagation velocity and fractal dimension velocity. It has been found that both crack propagation velocities $V$ and $V_{A_{\mathrm{p}}}$ increase with increasing $V_{D}$ for rocks under different impact velocities.

4.1.3. Crack Morphological Features. In addition to adopting the crack area $A_{\mathrm{P}}$ and fractal dimension $D$ to quantitatively describe the crack characteristics, two morphological features that can further analyze the crack evolution path and failure process are also proposed based on image processing technique. Figure 11 demonstrates a crack morphological process for crack initiation, propagation, and coalescence. In order to present a quantitative description of the distribution and shape factor of cracks, Anisometry and Compactness which derived from image morphology are proposed. In specific, Anisometry is derived from the geometric moments for each crack and defined as

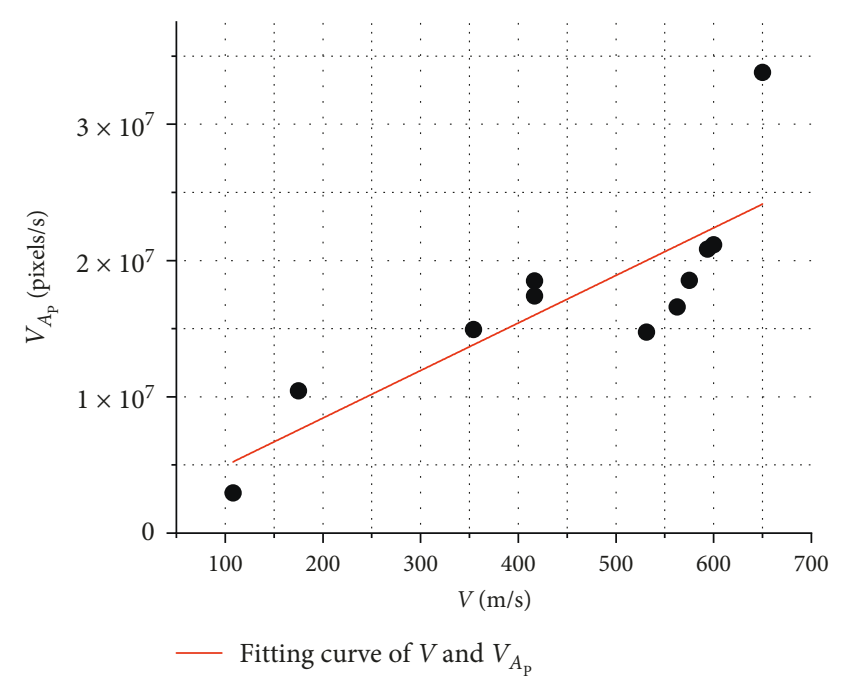

FIgURE 7: Relationship between $V$ and $V_{A_{\mathrm{p}}}$ of rock specimens under SHPB loading.

$$
\text { Anisometry }=\frac{R_{\mathrm{a}}}{R_{\mathrm{b}}},
$$

where $R_{\mathrm{a}}$ denotes the main radius of maximum ellipse of the crack and $R_{\mathrm{b}}$ represents the secondary radius of the ellipse. Similarly, Compactness is also a shape factor which value ranges from 0 to 1 and can be expressed as

$$
\begin{aligned}
\text { Compactness } & =\max \left(1, C^{\prime}\right), \\
C^{\prime} & =\frac{L^{2}}{4 \cdot F \cdot \pi},
\end{aligned}
$$

where $L$ is the total length of the contour and $F$ is the area of the region.

As shown in Figure 12(a), $V_{\text {Comp }}$ is decreasing with the increase of $V_{D}$ as a whole. It can also be seen from Figure 12(b) that the values of $V_{\text {Anis }}$ decrease almost linearly with the increase of impact velocity, which indicates that longitudinal crack length produced by the rock is less than transverse's under higher impact velocity.

4.1.4. Distribution of Cracks. It has been generally recognized that, for a valid and typical dynamic Brazilian 


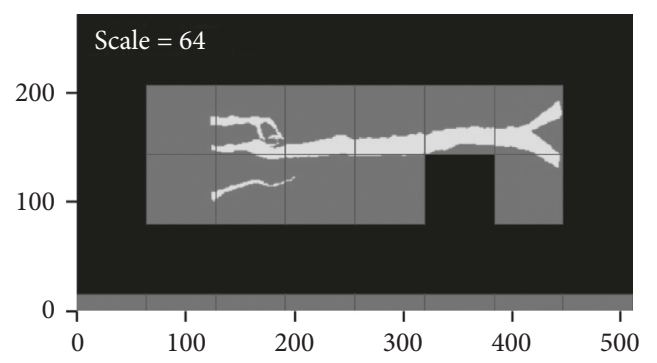

(a)

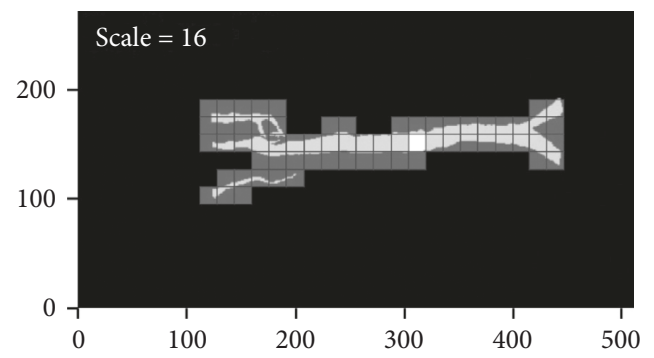

(c)

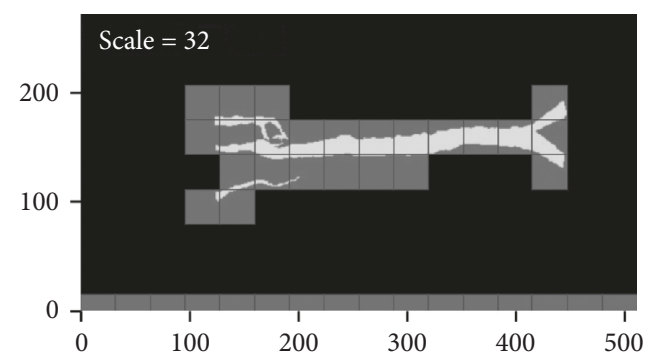

(b)

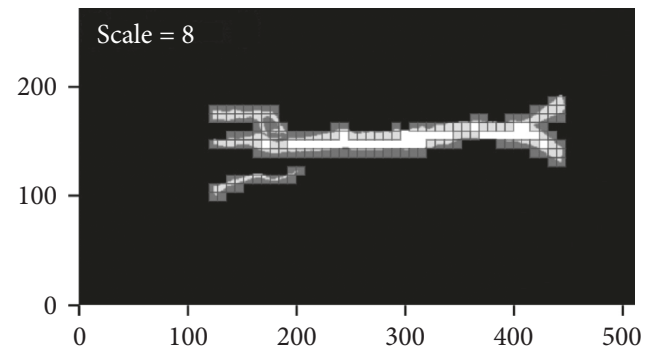

(d)

FIGURE 8: An illustration of different box scales to fully cover cracks.

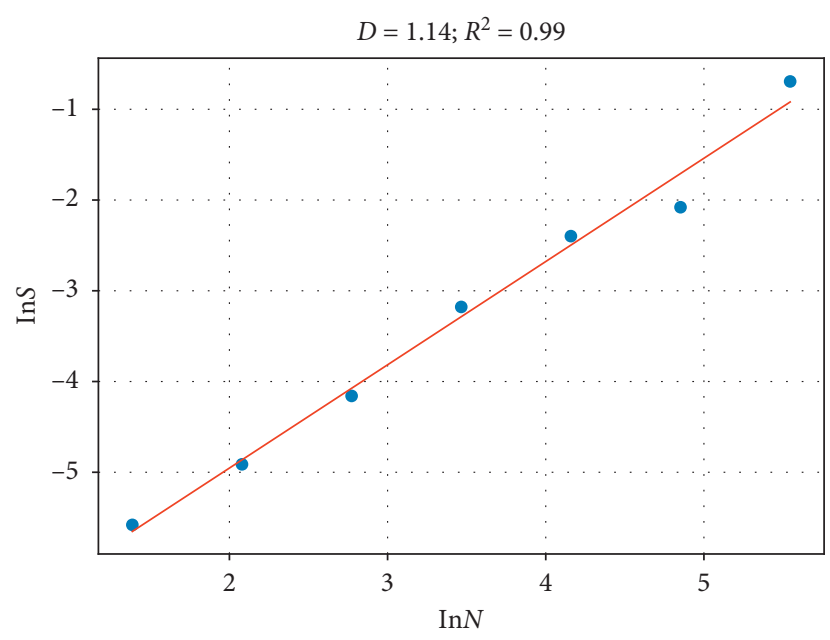

_ Fitting curve

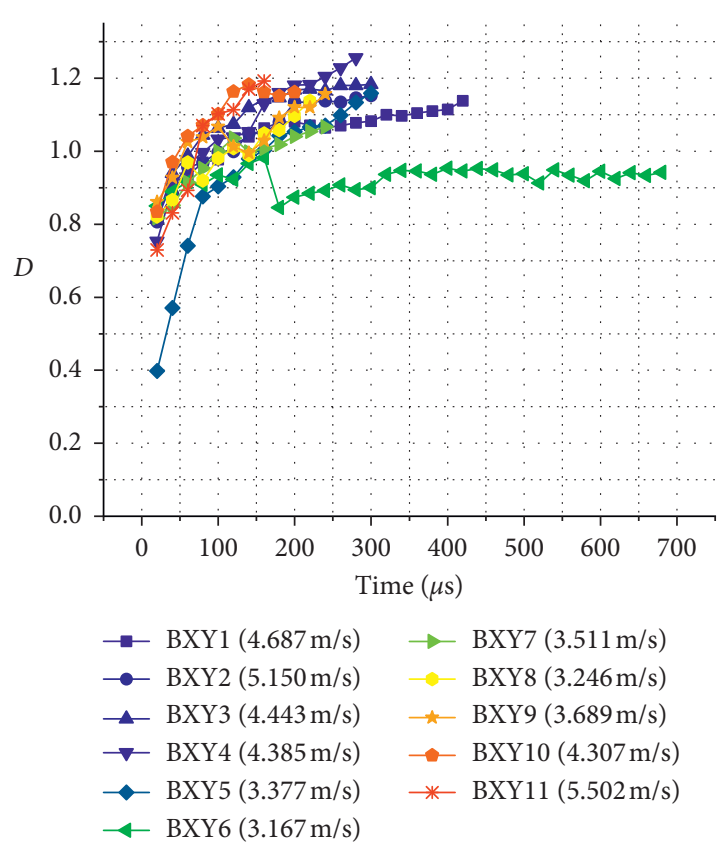

(b)

FiguRE 9: (a) Number of covered boxes versus box size; (b) fractal characteristics of crack for rock material under different velocities.

test, crack should be first appeared along the impact direction somewhere near the center of the specimen and then propagates bilaterally to the loading ends. According to the row and column index of the crack center, Figure 13 shows the coordinate distribution of crack center in the process of rock failure. It can be observed from Figure 13 that most of the rock disc cracks near the center of the specimen and the fracture propagation direction are bilateral to the loading ends and some cracks also appeared at the contact side of rock and bars. The result indicates that the failure patterns of dynamic Brazil test under SHPB loading approximately include tensile failure and shear failure. Accordingly, the cracks near the center of rocks are mainly caused by the tensile failure which is the main axial crack parallel to the loading direction, and other cracks are caused by the shear failure that is a result of secondary fractures due to the further compression. 


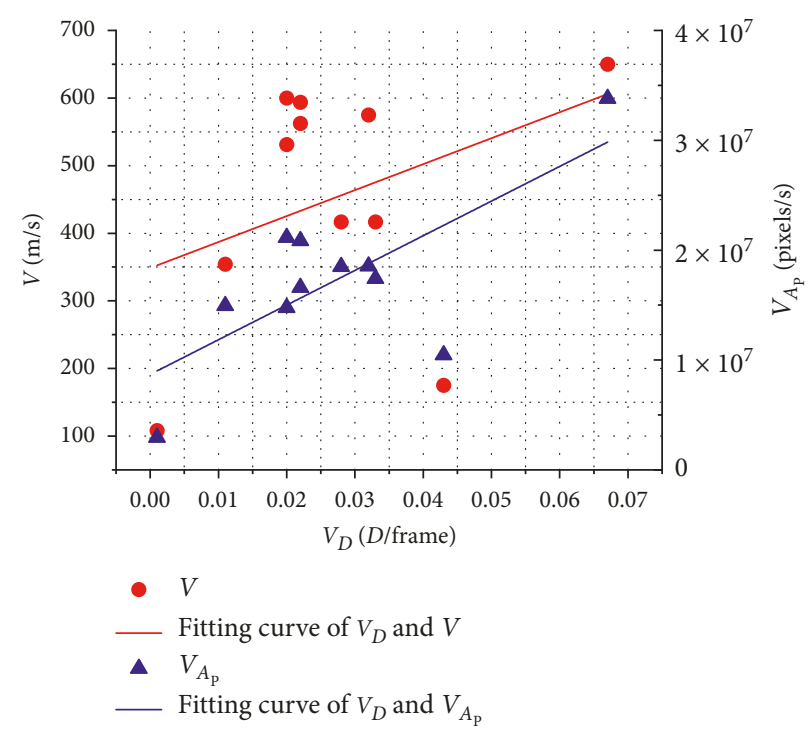

FIgURE 10: Relationship between $V, V_{A_{\mathrm{p}}}$, and $V_{D}$ in the SHPB experiment.

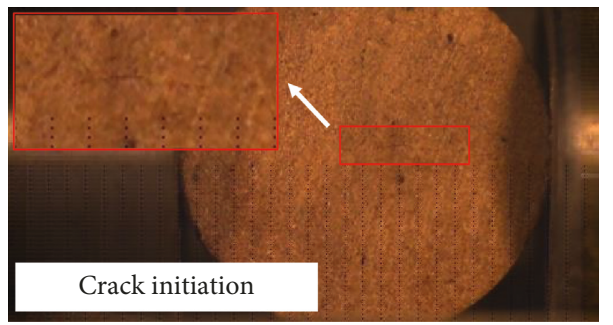

(a)

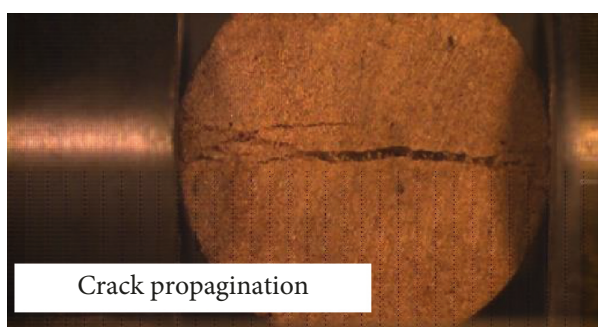

(c)

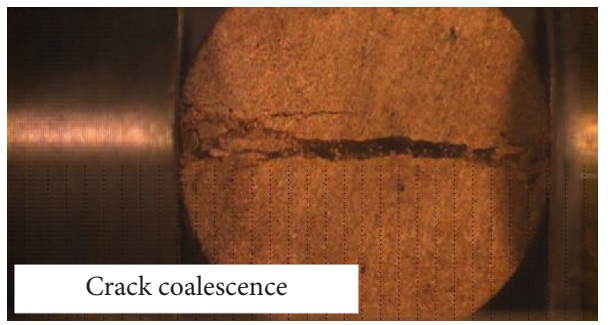

(e)

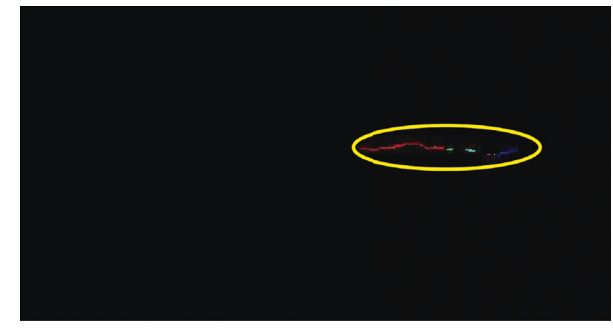

(b)

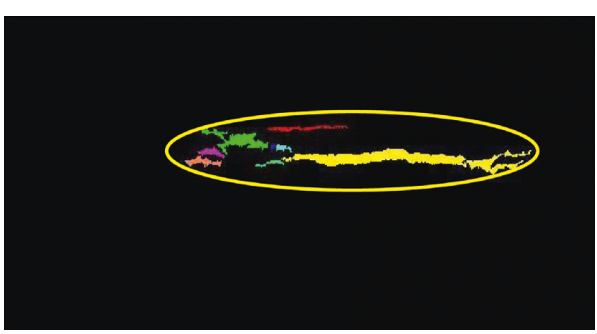

(d)

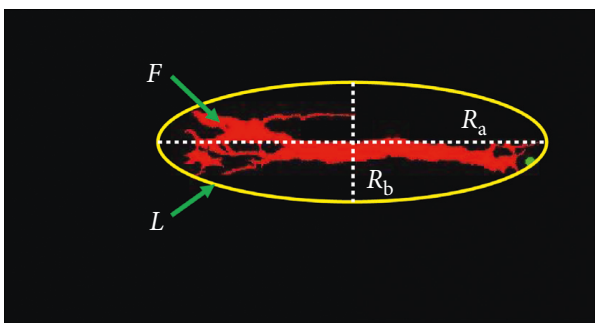

(f)

Figure 11: An illustration of crack morphological features. (a), (c), and (e) are original images represent crack initiation, propagation, and coalescence, respectively; (b), (d), and (f) are extracted cracks from corresponded images.

4.2. Dynamic Mechanical Properties. Figure 14 illustrates the incident $\varepsilon_{\mathrm{i}}(t)$, reflected $\varepsilon_{\mathrm{r}}(t)$, and transmitted $\varepsilon_{\mathrm{t}}(t)$ strain signals of rock specimens under different impact velocities during SHPB dynamic loading test. According to the three-wave analysis method, the mechanical properties of rocks under SHPB loading are determined. In this study, the absorbed energy and stress-strain parameters are calculated and further compared with crack 


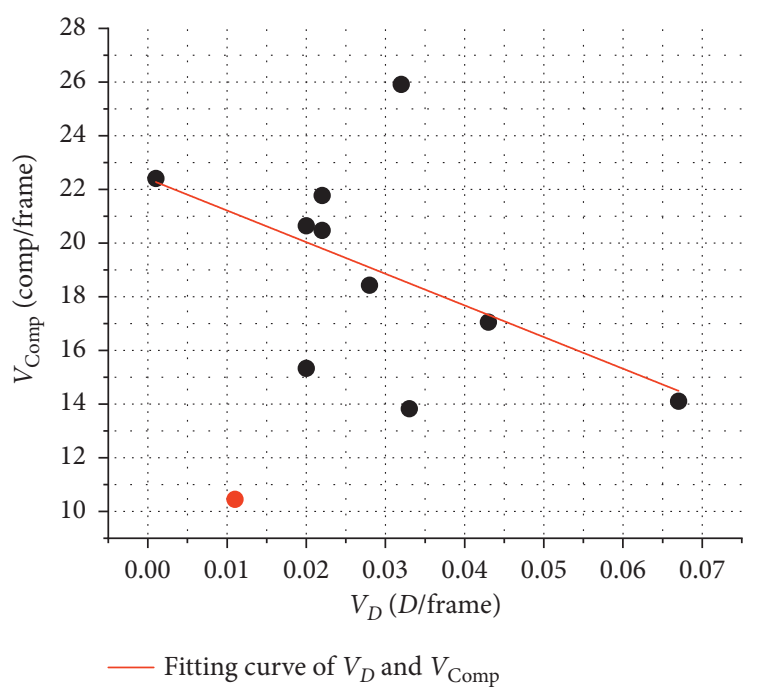

(a)

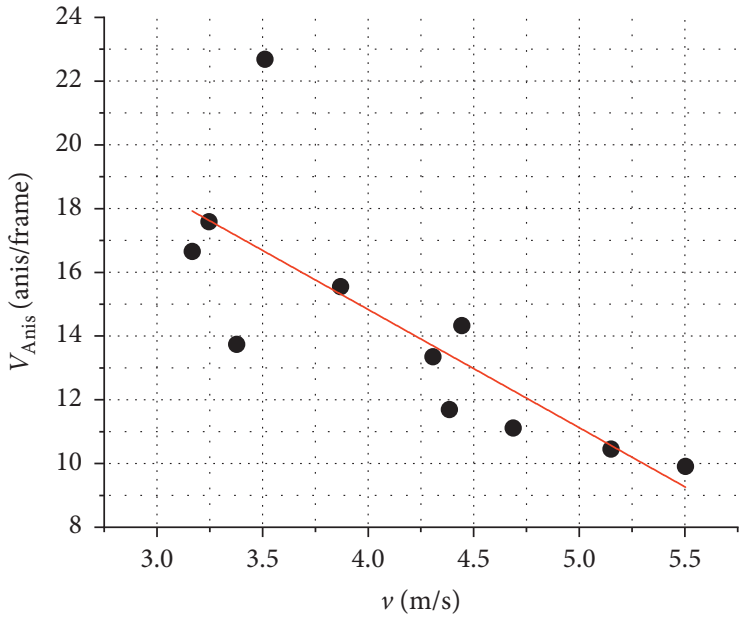

Fitting curve of $v$ and $V_{\text {Anis }}$

(b)

FIgURE 12: (a) Relationship between $V_{\text {Comp }}$ and $V_{D}$; (b) relationship between $V_{\text {Anis }}$ and $V$.

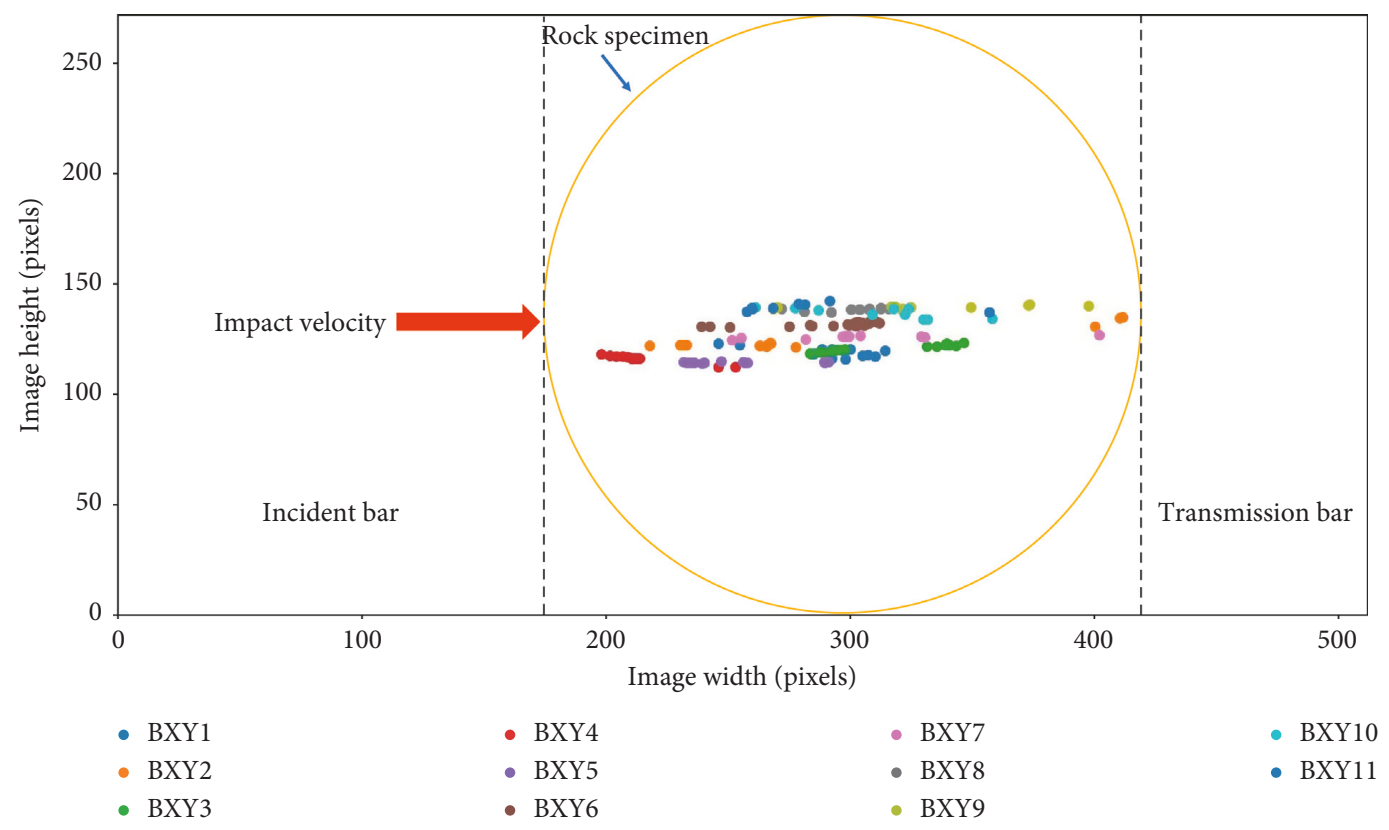

Figure 13: Crack distribution for rocks under different impact velocities.

propagation features to explore the relationship between them.

4.2.1. Dynamic Fracture Energy. It has been generally recognized that the fracture of rock under loading rates is the process of accumulation and dissipation of energy [57]. In specific, the consumed energy under SHPB dynamic loading can be well quantified based on the first law of thermodynamics [34]. During the SHPB dynamic loading test, the energy of the incident wave $W_{\mathrm{I}}$, the energy of the reflected wave $W_{\mathrm{R}}$, and the energy of the transmitted wave $W_{\mathrm{T}}$ can be computed as

$$
\begin{aligned}
W_{\mathrm{I}} & =\frac{A \cdot C}{E} \int \varepsilon_{\mathrm{i}}(t)^{2} d t, \\
W_{\mathrm{R}} & =\frac{A \cdot C}{E} \int \varepsilon_{\mathrm{r}}(t)^{2} d t, \\
W_{\mathrm{T}} & =\frac{A \cdot C}{E} \int \varepsilon_{\mathrm{t}}(t)^{2} d t,
\end{aligned}
$$

where $A$ is the cross-sectional area, $C$ is the longitudinal wave speed, and $E$ is Young's modulus of the bars.

Assuming that all the energy loss at the specimen and bar interfaces can be negligible, the energy absorbed by the rock specimen $W_{\mathrm{S}}$ can be expressed as 


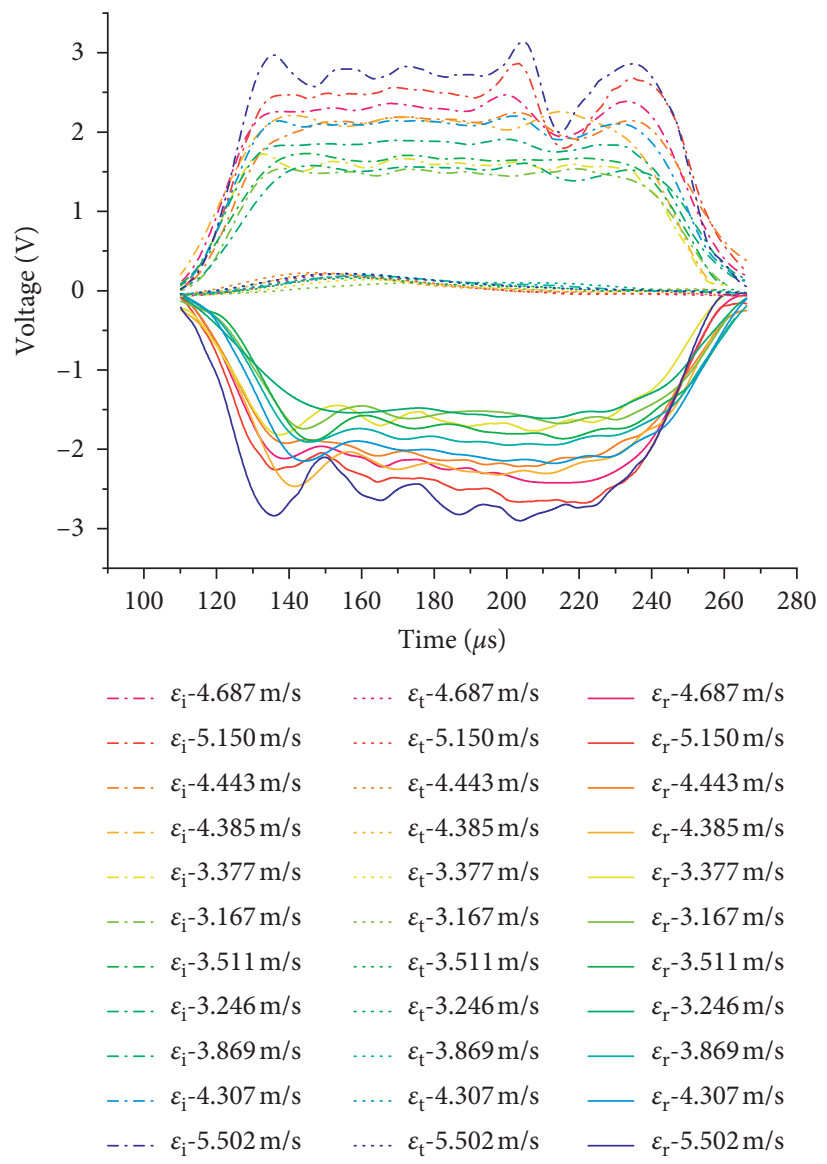

FIGURE 14: Incident, reflected, and transmitted signals of rocks under different impact velocities.

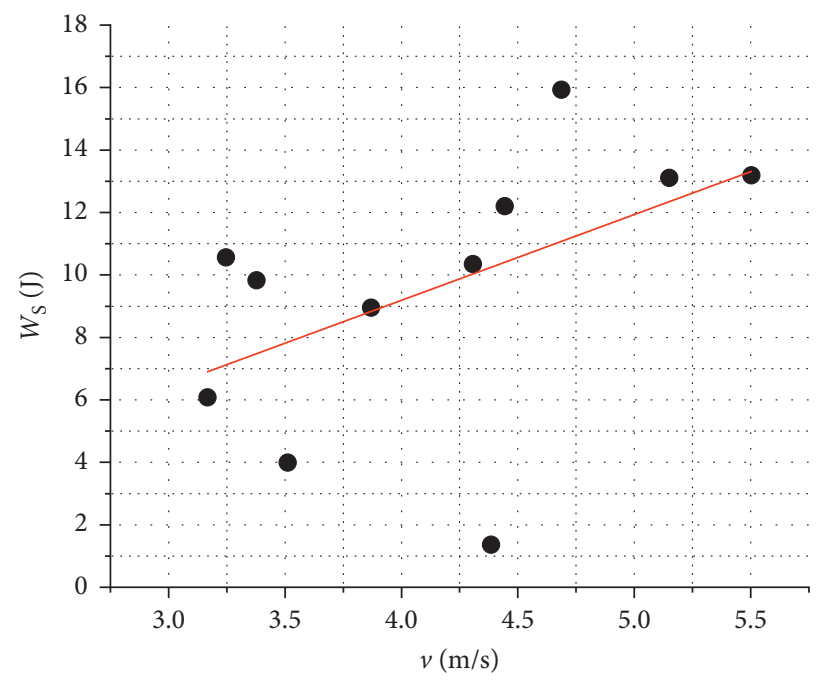

Fitting curve of $v$ and $W_{\mathrm{S}}$

FIGURE 15: Relationship between $v$ and $W_{S}$.

$$
W_{\mathrm{S}}=W_{\mathrm{I}}-W_{\mathrm{R}}-W_{\mathrm{T}}
$$

Figure 15 shows the total energy absorbed versus the impact velocity for the rock specimens. It indicates that the energy absorbed by the rock specimen increases with increasing impact velocity.

Moreover, substantial efforts have been devoted to performing quantitative measurements on fracture surface, and it 


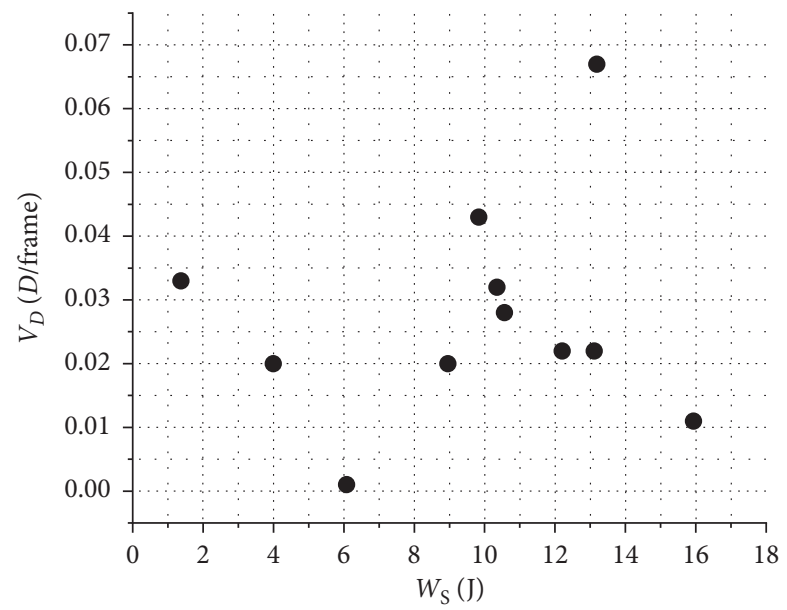

(a)

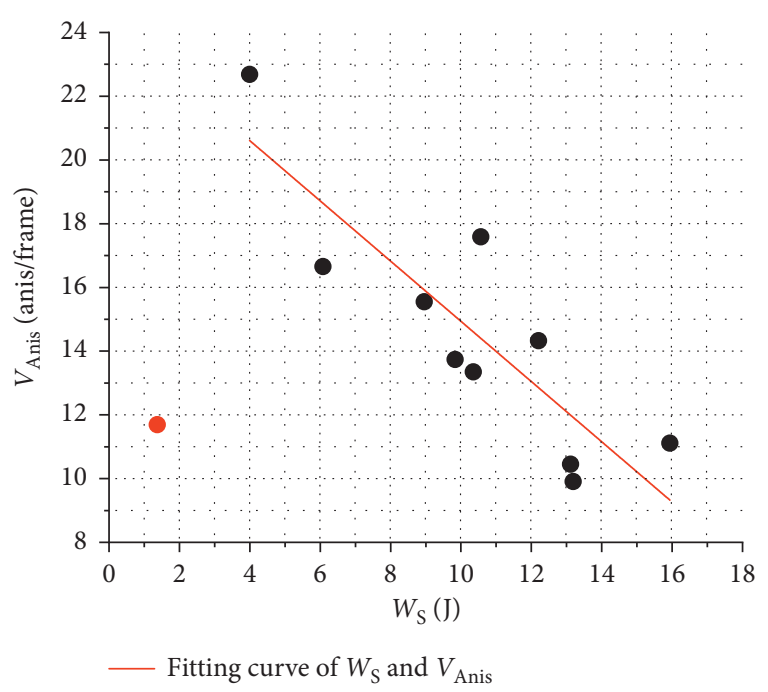

(b)

Figure 16: (a) Relationship between $W_{\mathrm{S}}$ and $V_{D}$; (b) relationship between $W_{\mathrm{S}}$ and $V_{\text {Anis }}$.

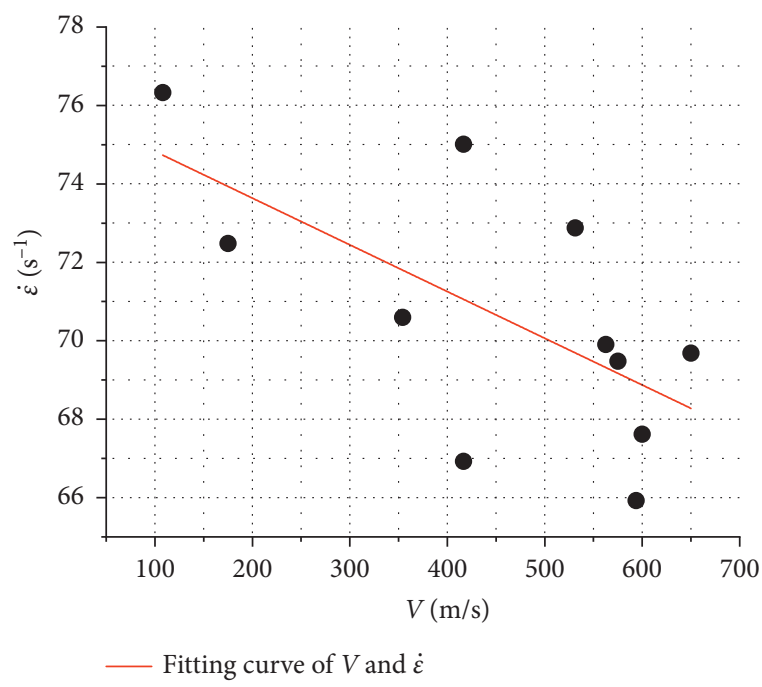

(a)

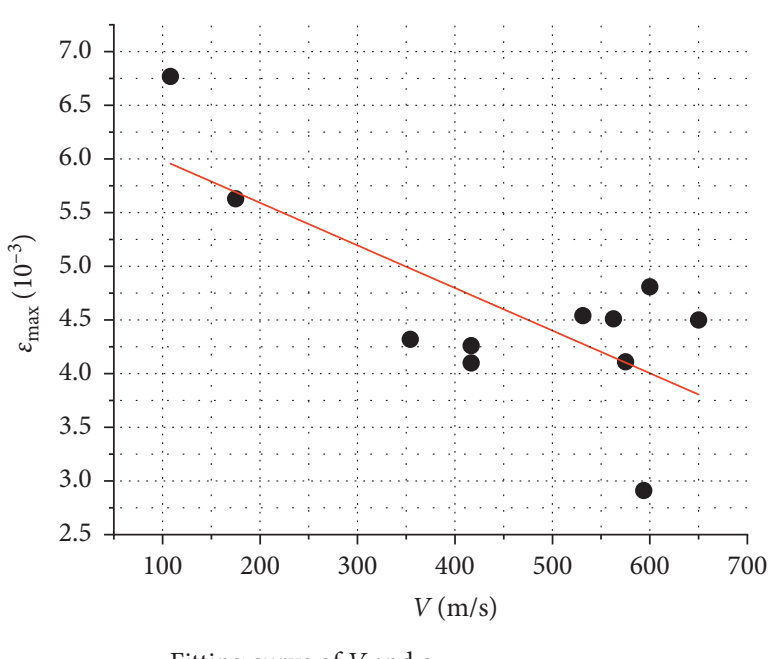

(b)

FIGURE 17: Curves of strain parameters with crack propagation velocity $V$ and associated results after linear fitting. (a) $\dot{\varepsilon}$ as a function of $V$; (b) $\varepsilon_{\max }$ as a function of $V$.

has been well recognized that surface roughness in rock-like materials exhibits self-similarity properties at least over a given range of length scales. In other words, the fracture surface topography of rock-like materials reveals inherent details associated with energy dissipation mechanisms that govern the fracturing process. Therefore, the relationship between fractal dimension and absorbed energy was first calculated, and the result is shown in Figure 16(a). However, it can be found that there is no obvious relationship between the two variables.

On the other hand, Figure 16(b) presents the total energy absorbed $W_{\mathrm{S}}$ versus the crack feature $V_{\text {Anis }}$ for the rock specimens. It can be seen that there is a linearly negative correlation between the two variables, the greater the $W_{S}$, the smaller the $V_{\text {Anis }}$.
4.2.2. Strain-Stress Parameters. According to the incident $\varepsilon_{\mathrm{i}}(t)$, reflected $\varepsilon_{\mathrm{r}}(t)$, and transmitted $\varepsilon_{\mathrm{t}}(t)$ strain signals illustrated in Figure 14 and formulas (1)-(3), the max stress, max strain, and mean strain rate of rocks under different impact velocities were calculated. Combining with the crack characteristic parameters in the above section, the relationship between the crack propagation process and dynamic mechanical properties was analyzed.

Figure 17 shows the max strain and mean strain rate versus the crack propagation velocity $V$, while Figure 18 shows the max strain and mean strain rate versus the crack propagation velocity $V_{A_{\mathrm{p}}}$. It can be seen that, with the increase of the $V$, both the max strain and mean strain rate are gradually decreased and mean strain rate basically 


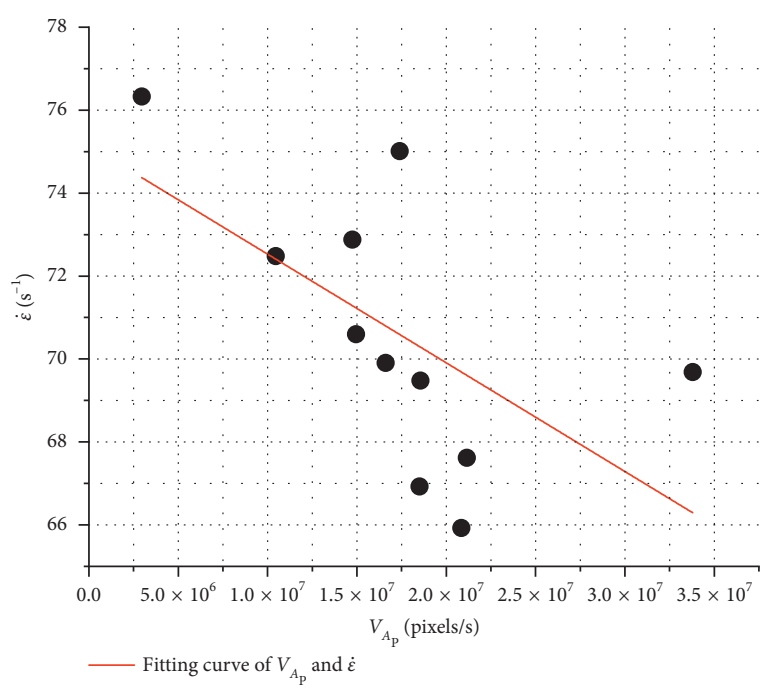

(a)

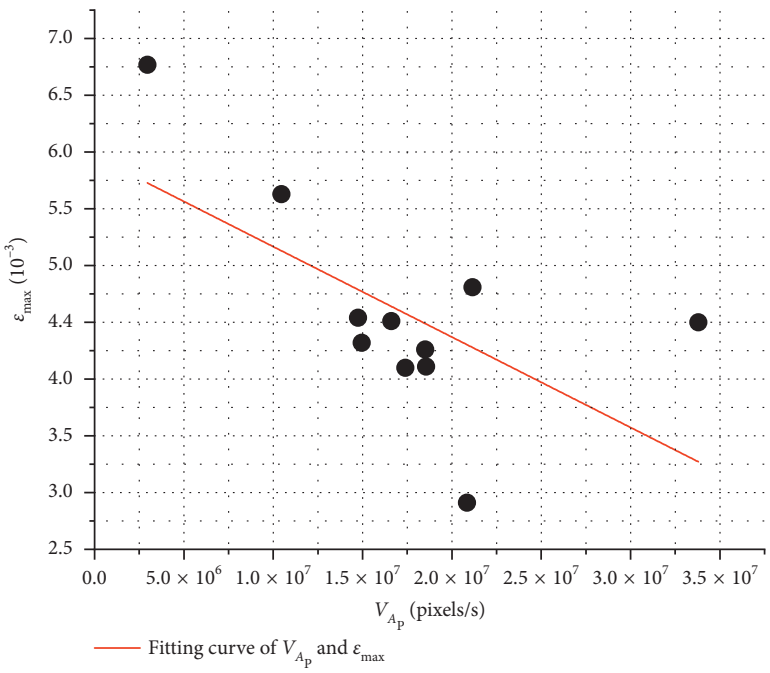

(b)

FIGURE 18: Curves of strain parameters with crack propagation velocity $V_{A_{\mathrm{P}}}$ and associated results after linear fitting. (a) $\dot{\varepsilon}$ as a function of $V_{A_{\mathrm{p}}}$; (b) $\varepsilon_{\max }$ as a function of $V_{A_{\mathrm{p}}}$.

remains the same when $V$ ranges from $350 \mathrm{~m} / \mathrm{s}$ to $650 \mathrm{~m} / \mathrm{s}$. Similarly, the max strain and mean strain rate also linearly decrease with the increase of crack propagation velocity $V_{A_{\mathrm{P}}}$.

\section{Conclusion}

In this study, the Brazil test of rock specimens was performed under different impact velocities using the SHPB system to explore fracture characterizations of rocks under dynamic loads. Based on image processing technique, crack propagation process was quantitatively described from three perspectives: the crack propagation velocity, crack fractal characteristic, and crack morphological features. According to the recorded strain wave signals, the dynamic mechanical properties of rocks were also calculated, and the relationship between impact velocity and crack propagation process was explored and analyzed. The main conclusions are listed as follows:

(1) Crack propagation velocities $V$ and $V_{A_{\mathrm{p}}}$ both increase with increase of the crack fractals velocity $V_{D}$

(2) The proposed two crack features, Compactness and Anisometery, have a capacity of describing the fracture process of rock. In specific, $V_{\text {Anis }}$ linearly decreases with the increase of impact velocity $v$ while $V_{\text {Comp }}$ exhibits a negative relationship with crack fractals velocity $V_{D}$

(3) The energy absorbed by the rocks increases with the increase of impact velocity $v$ but shows a linear negative trend with $V_{\text {Anis }}$

(4) The mean strain rate and max strain both decrease with increase of crack propagation velocity, which shows that there is a certain relationship between the crack propagation process and dynamic mechanical properties of rocks under dynamic loading
In the future work, we will conduct the static tensile tests using the $\mathrm{BD}$ specimen on the same rock material and compare the static and dynamic results in terms of mechanical properties and crack propagation process.

\section{Nomenclature}

$\dot{\varepsilon}: \quad$ Mean strain rate $\left(\mathrm{s}^{-1}\right)$

$\sigma_{\text {max }}: \quad$ Max stress $(\mathrm{MPa})$

$\varepsilon_{\max }: \quad$ Max strain $\left(10^{-3}\right)$

A: $\quad$ Cross-sectional area of the bar $\left(\mathrm{mm}^{2}\right)$

A: $\quad$ Crack length ( $\mathrm{mm})$

$A_{\mathrm{p}}: \quad$ Crack quantification area (pixels)

$A_{\mathrm{S}}$ : $\quad$ Cross-sectional area of the specimen $\left(\mathrm{mm}^{2}\right)$

Anis: Crack feature descriptor-anisometry

C: $\quad$ Longitudinal stress wave speed of the bar $(\mathrm{m} / \mathrm{s})$

Comp: Crack feature descriptor-compactness

D: $\quad$ Fractal dimension

E: $\quad$ Young's modulus of the bar $(\mathrm{GPa})$

$L_{S}: \quad$ Length of rock specimen $(\mathrm{mm})$

$P_{1}, P_{2}$ : Dynamic forces on incident and transmitted ends (N)

$r_{x y}: \quad$ Pearson's correlation coefficient

$V: \quad$ Crack propagation velocity $(\mathrm{m} / \mathrm{s})$

$v: \quad$ Impact velocity $(\mathrm{m} / \mathrm{s})$

$V_{D}: \quad$ Fractal dimension velocity ( $D /$ frame $)$

$V_{A_{\mathrm{p}}}: \quad$ Crack propagation velocity (pixels/s)

$V_{\text {Anis }}:$ Anisometry velocity (anis/frame)

$V_{\text {Comp }}$ : Compactness velocity (comp/frame)

$W_{\mathrm{S}}: \quad$ Absorbed energy $(\mathrm{J})$.

\section{Data Availability}

The data utilized in this study are available from the corresponding author upon request. 


\section{Conflicts of Interest}

The authors declare that they have no conflicts of interest.

\section{Acknowledgments}

This research was financially supported by the National Natural Science Foundation of China (nos. 51274206 and 51404277). This support is greatly acknowledged and appreciated.

\section{References}

[1] K. Xia and W. Yao, "Dynamic rock tests using split Hopkinson (Kolsky) bar system-a review," Journal of Rock Mechanics and Geotechnical Engineering, vol. 7, no. 1, pp. 27-59, 2015.

[2] F. Gong, H. Ye, and Y. Luo, "The effect of high loading rate on the behaviour and mechanical properties of coal-rock combined body," Shock and Vibration, vol. 2018, Article ID 4374530, 9 pages, 2018.

[3] Y. X. Zhou, K. Xia, X. B. Li et al., "Suggested methods for determining the dynamic strength parameters and mode- $\mathrm{i}$ fracture toughness of rock materials," International Journal of Rock Mechanics and Mining Sciences, vol. 49, no. 1, pp. 105-112, 2012.

[4] Y. Zhao, G.-F. Zhao, Y. Jiang, D. Elsworth, and Y. Huang, "Effects of bedding on the dynamic indirect tensile strength of coal. Laboratory experiments and numerical simulation," International Journal of Coal Geology, vol. 132, pp. 81-93, 2014.

[5] F. Dai, K. Xia, and S. N. Luo, "Semicircular bend testing with split Hopkinson pressure bar for measuring dynamic tensile strength of brittle solids," Review of Scientific Instruments, vol. 79, no. 12, article 123903, 2008.

[6] F. Dai, K. Xia, and L. Tang, "Rate dependence of the flexural tensile strength of Laurentian granite," International Journal of Rock Mechanics and Mining Sciences, vol. 47, no. 3, pp. 469-475, 2010.

[7] Y. Wang, "Rock dynamic fracture characteristics based on NSCB impact method," Shock and Vibration, vol. 2018, Article ID 3105384, 13 pages, 2018.

[8] Q. B. Zhang and J. Zhao, "Effect of loading rate on fracture toughness and failure micromechanisms in marble," Engineering Fracture Mechanics, vol. 102, pp. 288-309, 2013.

[9] M. D. Kuruppu, Y. Obara, M. R. Ayatollahi, K. P. Chong, and T. Funatsu, "ISRM-suggested method for determining the mode i static fracture toughness using semi-circular bend specimen," Rock Mechanics and Rock Engineering, vol. 47, no. 1, pp. 267-274, 2014.

[10] M. R. M. Aliha and M. R. Ayatollahi, "Rock fracture toughness study using cracked chevron notched Brazilian disc specimen under pure modes I and II loading-a statistical approach," Theoretical and Applied Fracture Mechanics, vol. 69, no. 2, pp. 17-25, 2014.

[11] F. Dai, K. Xia, H. Zheng, and Y. X. Wang, "Determination of dynamic rock mode-i fracture parameters using cracked chevron notched semi-circular bend specimen," Engineering Fracture Mechanics, vol. 78, no. 15, pp. 2633-2644, 2011.

[12] T. Tang, Z. P. Bažant, S. Yang, and D. Zollinger, "Variablenotch one-size test method for fracture energy and process zone length," Engineering Fracture Mechanics, vol. 55, no. 3, pp. 383-404, 1996.
[13] Q. Z. Wang, S. Zhang, and H. P. Xie, "Rock dynamic fracture toughness tested with holed-cracked flattened Brazilian discs diametrically impacted by SHPB and its size effect," Experimental Mechanics, vol. 50, no. 7, pp. 877-885, 2010.

[14] B. Lundberg, "A split Hopkinson bar study of energy absorption in dynamic rock fragmentation," International Journal of Rock Mechanics and Mining Sciences \& Geomechanics Abstracts, vol. 13, no. 6, pp. 187-197, 1976.

[15] V. Isheyskiy and M. Marinin, "Determination of rock mass weakening coefficient after blasting in various fracture zones," Engineering Solid Mechanics, vol. 5, no. 3, pp. 199-204, 2017.

[16] G. Gary and P. Bailly, "Behaviour of quasi-brittle material at high strain rate. Experiment and modelling," European Journal of Mechanics-A/Solids, vol. 17, no. 3, pp. 403-420, 1998.

[17] J. Zhao, H. B. Li, and Y. H. Zhao, Dynamic Strength Tests of the Bukit Timah Granite, Nanyang Technological University, Singapore, 1998.

[18] Q. B. Zhang and J. Zhao, "A review of dynamic experimental techniques and mechanical behaviour of rock materials," Rock Mechanics and Rock Engineering, vol. 47, no. 4, pp. 1411-1478, 2014.

[19] J. Zhao and H. B. Li, "Experimental determination of dynamic tensile properties of a granite," International Journal of Rock Mechanics and Mining Sciences, vol. 37, no. 5, pp. 861-866, 2000.

[20] J. R. Klepaczko and A. Brara, "An experimental method for dynamic tensile testing of concrete by spalling," International Journal of Impact Engineering, vol. 25, no. 4, pp. 387-409, 2001.

[21] S. Kubota, Y. Ogata, Y. Wada, G. Simangunsong, H. Shimada, and K. Matsui, "Estimation of dynamic tensile strength of sandstone," International Journal of Rock Mechanics and Mining Sciences, vol. 45, no. 3, pp. 397-406, 2008.

[22] B. Erzar and P. Forquin, "An experimental method to determine the tensile strength of concrete at high rates of strain," Experimental Mechanics, vol. 50, no. 7, pp. 941-955, 2010.

[23] L. Biolzi and J. Labuz, "Instabilities in fracture of elasticsoftening structures," Fracture of Engineering Materials and Structures, vol. 6, no. 8, pp. 821-826, 1991.

[24] Q. Z. Wang, W. Li, and H. P. Xie, "Dynamic split tensile test of flattened Brazilian disc of rock with SHPB setup," Mechanics of Materials, vol. 41, no. 3, pp. 252-260, 2009.

[25] D. Asprone, E. Cadoni, A. Prota, and G. Manfredi, “Dynamic behavior of a mediterranean natural stone under tensile loading," International Journal of Rock Mechanics and Mining Sciences, vol. 46, no. 3, pp. 514-520, 2009.

[26] H. Kolsky, "An investigation of the mechanical properties of materials at very high rates of loading," Proceedings of the Physical Society. Section B, vol. 62, no. 11, pp. 676-700, 1949.

[27] U. S. Lindholm, "Some experiments with the split Hopkinson pressure bar," Journal of the Mechanics and Physics of Solids, vol. 12, no. 5, pp. 317-335, 1964.

[28] G. Subhash and G. Ravichandran, Split-Hopkinson Pressure Bar Testing of Ceramics, pp. 497-504, ASM International, Materials Park, OH, USA, 2000.

[29] X. Li, T. Zhou, D. Li, and Z. Wang, "Experimental and numerical investigations on feasibility and validity of prismatic rock specimen in SHPB," Shock and Vibration, vol. 2016, Article ID 7198980, 13 pages, 2016.

[30] M. R. Ayatollahi and M. Sistaninia, "Mode II fracture study of rocks using Brazilian disk specimens," International Journal of Rock Mechanics and Mining Sciences, vol. 48, no. 5, pp. 819-826, 2011. 
[31] Q. Z. Wang, X. P. Gou, and H. Fan, "The minimum dimensionless stress intensity factor and its upper bound for CCNBD fracture toughness specimen analyzed with straight through crack assumption," Engineering Fracture Mechanics, vol. 82, pp. 1-8, 2012.

[32] Q. B. Zhang and J. Zhao, "Quasi-static and dynamic fracture behaviour of rock materials: phenomena and mechanisms," International Journal of Fracture, vol. 189, no. 1, pp. 1-32, 2014.

[33] A. Bertram and J. F. Kalthoff, "Crack propagation toughness of rock for the range of low to very high crack speeds," Key Engineering Materials, vol. 251-252, pp. 423-430, 2003.

[34] R. Chen, K. Xia, F. Dai, F. Lu, and S. N. Luo, "Determination of dynamic fracture parameters using a semi-circular bend technique in split Hopkinson pressure bar testing," Engineering Fracture Mechanics, vol. 76, no. 9, pp. 1268-1276, 2009.

[35] P. Forquin, "An optical correlation technique for characterizing the crack velocity in concrete," The European Physical Journal Special Topics, vol. 206, no. 1, pp. 89-95, 2012.

[36] Y. Zhao, S. Gong, C. Zhang, Z. Zhang, and Y. Jiang, "Fractal characteristics of crack propagation in coal under impact loading," Fractals, vol. 26, no. 2, article 1840014, 2018.

[37] J. T. Gomez, A. Shukla, and A. Sharma, "Static and dynamic behavior of concrete and granite in tension with damage," Theoretical and Applied Fracture Mechanics, vol. 36, no. 1, pp. 37-49, 2001.

[38] Q. B. Zhang and J. Zhao, "Determination of mechanical properties and full-field strain measurements of rock material under dynamic loads," International Journal of Rock Mechanics and Mining Sciences, vol. 60, pp. 423-439, 2013.

[39] W. Yao, Y. Xu, H.-W. Liu, and K. Xia, "Quantification of thermally induced damage and its effect on dynamic fracture toughness of two mortars," Engineering Fracture Mechanics, vol. 169, pp. 74-88, 2017.

[40] T. S. Yun, Y. J. Jeong, K. Y. Kim, and K.-B. Min, "Evaluation of rock anisotropy using 3D X-ray computed tomography," Engineering Geology, vol. 163, pp. 11-19, 2013.

[41] T. Yin, X. Li, K. Xia, and S. Huang, "Effect of thermal treatment on the dynamic fracture toughness of Laurentian granite," Rock Mechanics and Rock Engineering, vol. 45, no. 6, pp. 1087-1094, 2012.

[42] S. Huang, K. Xia, F. Yan, and X. Feng, "An experimental study of the rate dependence of tensile strength softening of Longyou sandstone," Rock Mechanics and Rock Engineering, vol. 43, no. 6, pp. 677-683, 2010.

[43] S. N. Luo, B. J. Jensen, D. E. Hooks et al., "Gas gun shock experiments with single-pulse $\mathrm{X}$-ray phase contrast imaging and diffraction at the advanced photon source," Review of Scientific Instruments, vol. 83, no. 7, article 073903, 2012.

[44] M. Hudspeth, B. Claus, S. Dubelman et al., "High speed synchrotron X-ray phase contrast imaging of dynamic material response to split Hopkinson bar loading," Review of Scientific Instruments, vol. 84, no. 2, article 025102, 2013.

[45] Y. Li and K. T. Ramesh, "An optical technique for measurement of material properties in the tension Kolsky bar," International Journal of Impact Engineering, vol. 34, no. 4, pp. 784-798, 2007.

[46] G. Gao, S. Huang, K. Xia, and Z. Li, "Application of digital image correlation (DIC) in dynamic notched semi-circular bend (NSCB) tests," Experimental Mechanics, vol. 55, no. 1, pp. 95-104, 2015.

[47] B. Pan, K. Qian, H. Xie, and A. Asundi, "Two-dimensional digital image correlation for in-plane displacement and strain measurement: a review," Measurement Science and Technology, vol. 20, no. 6, article 062001, 2009.

[48] F. Amiot, M. Bornert, P. Doumalin et al., "Assessment of digital image correlation measurement accuracy in the ultimate error regime: main results of a collaborative benchmark," Strain, vol. 49, no. 6, pp. 483-496, 2013.

[49] W. Shi, Y. Wu, and L. Wu, "Quantitative analysis of the projectile impact on rock using infrared thermography," International Journal of Impact Engineering, vol. 34, no. 5, pp. 990-1002, 2007.

[50] D. K. Iakovidis, T. Goudas, C. V. Smailis, and I. Maglogiannis, "Ratsnake: a versatile image annotation tool with application to computer-aided diagnosis," The Scientific World Journal, vol. 2014, Article ID 286856, 12 pages, 2014.

[51] B. A. Han, H. Y. Xiang, Z. Li, and J. J. Huang, "Defects detection of sheet metal parts based on HALCON and region morphology," Applied Mechanics and Materials, vol. 365-366, pp. 729-732, 2013.

[52] D. Ai, Y. Zhao, Q. Wang, and C. Li, "Experimental and numerical investigation of crack propagation and dynamic properties of rock in SHPB indirect tension test," International Journal of Impact Engineering, vol. 126, pp. 135146, 2019.

[53] H. Xie and D. J. Sanderson, "Fractal effects of crack propagation on dynamic stress intensity factors and crack velocities," International Journal of Fracture, vol. 74, no. 1, pp. 29-42, 1996.

[54] F. Dai, R. Chen, and K. Xia, "A semi-circular bend technique for determining dynamic fracture toughness," Experimental Mechanics, vol. 50, no. 6, pp. 783-791, 2010.

[55] D. Chakerian and B. B. Mandelbrot, "The fractal geometry of nature," College Mathematics Journal, vol. 15, no. 2, pp. 175-177, 1984.

[56] K. Falconer, "Fractal geometry: mathematical foundations and applications," Biometrics, vol. 46, no. 3, pp. 886-887, 1990.

[57] T.-B. Yin, K. Peng, L. Wang, P. Wang, X.-Y. Yin, and Y.-L. Zhang, "Study on impact damage and energy dissipation of coal rock exposed to high temperatures," Shock and Vibration, vol. 2016, Article ID 5121932, 10 pages, 2016. 


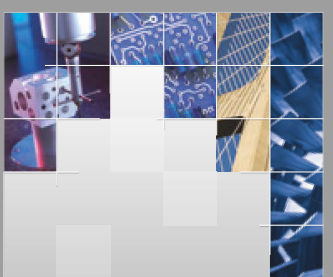

\section{Enfincering}
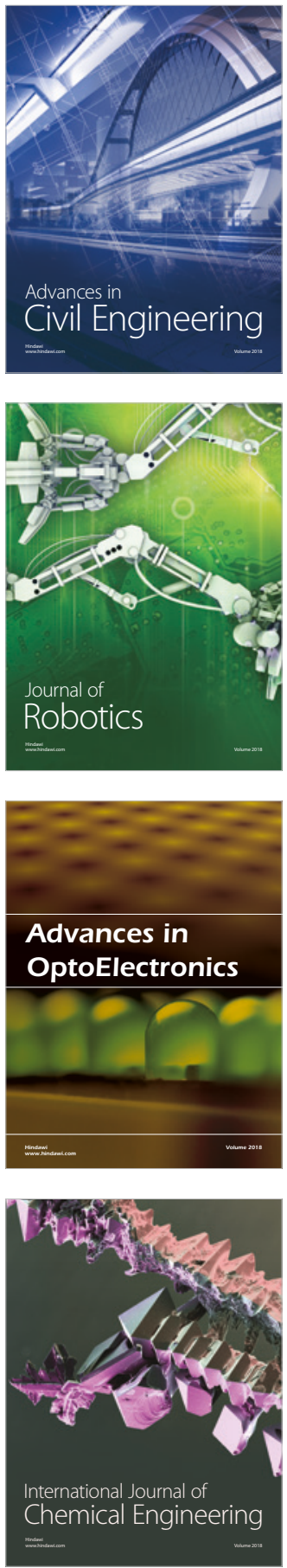

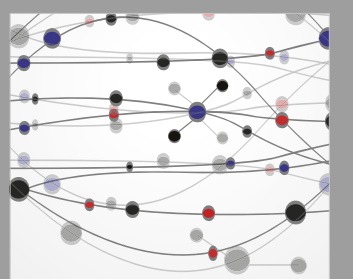

\section{Rotating \\ Machinery}

The Scientific World Journal

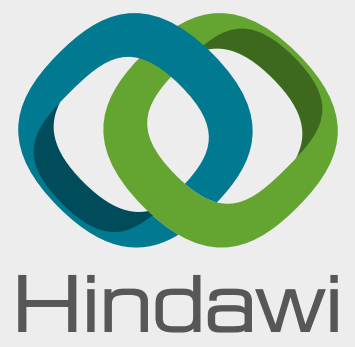

Submit your manuscripts at

www.hindawi.com
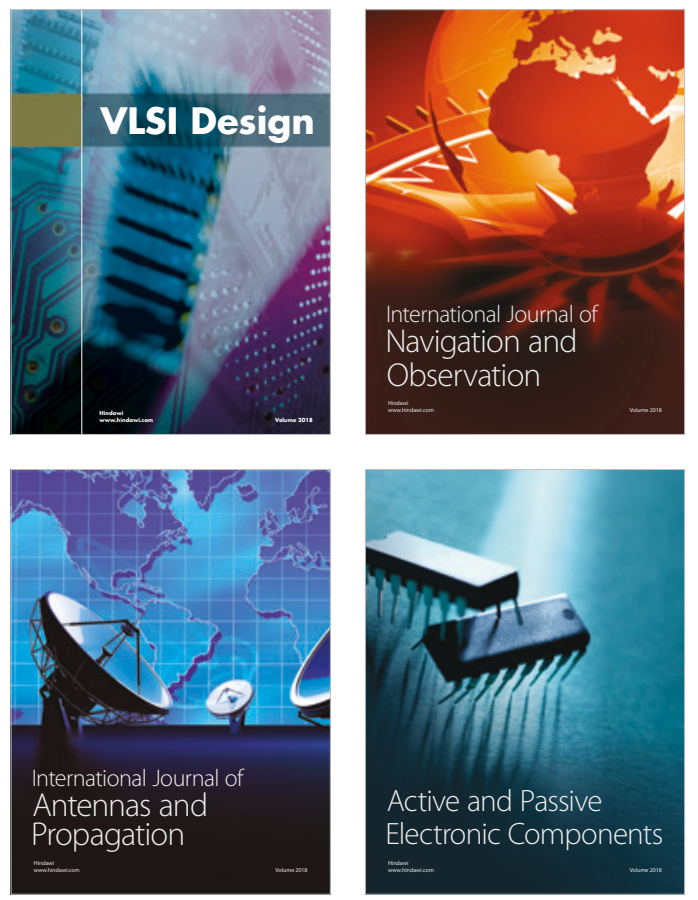
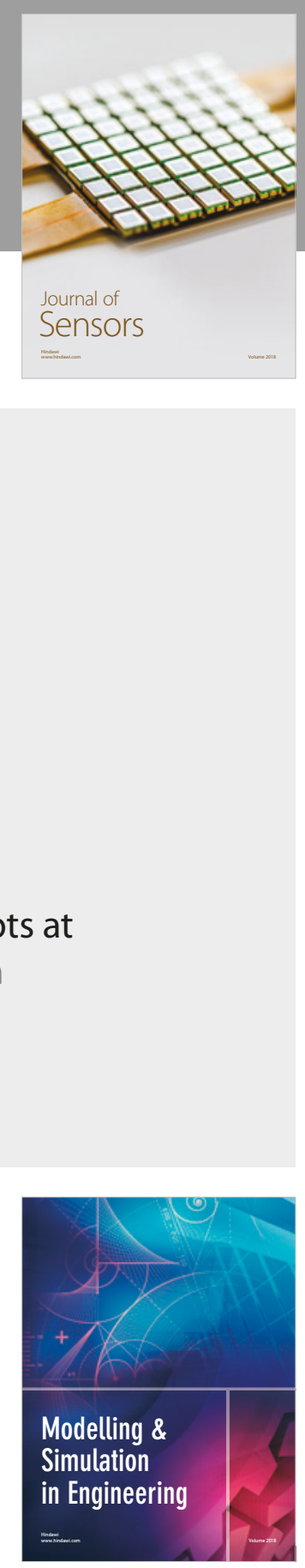

\section{Advances \\ Multimedia}
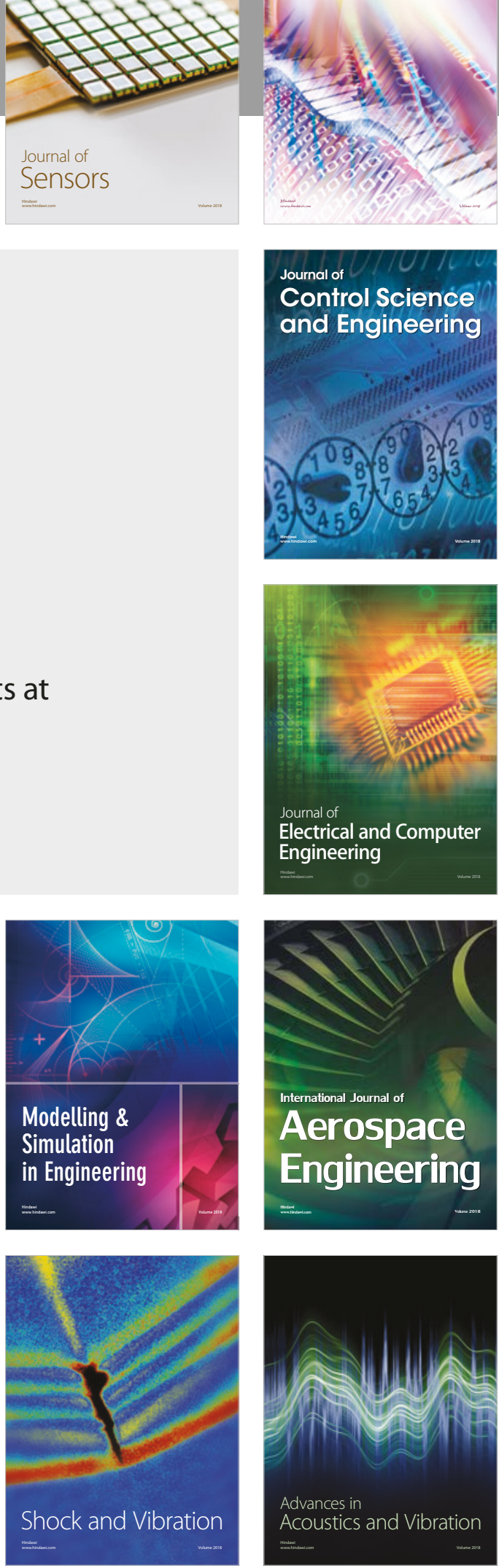